\title{
Analysis of Electrolyte Level Change in a Lithium Air Battery
}

\author{
Jing Huang ${ }^{\text {a, } *}$, Amir Faghri ${ }^{\text {a }}$ \\ ${ }^{a}$ Department of Mechanical Engineering, University of Connecticut, 191 Auditorium Road, Unit \\ 3139, Storrs, CT 06269, Storrs, CT 06269, USA \\ * Corresponding author: \\ Department of Mechanical Engineering \\ University of Connecticut \\ 191 Auditorium Road, Unit 3139 \\ Storrs, CT 06269, USA \\ Phone: +1-860-486-2205 \\ Fax: +1-860-486-0479 \\ E-mail address: \\ jing.huang@engineer.uconn.edu (J.Huang) \\ faghri@engr.uconn.edu (A. Faghri)
}

Keywords: Lithium air battery; Deformed mesh; Modeling; Electrolyte level

Word count: 4960

Number of tables: 4

Number of figures: 8 


\begin{abstract}
A two-dimensional physical model that employs the deformed mesh method to track the electrolyte level in a Li-air coin cell battery is presented and used to investigate the effects of electrolyte level drop during cell discharge. The electrolyte level drop is caused by solid phase volume decrease and electrolyte solvent evaporation. Simulation results show that by neglecting the drop in electrolyte level, a Li-air battery model would under-estimate cell discharge capacity by as much as $22.5 \%$ in the parameter range studied. This counter-intuitive result is explained by an in-depth analysis of simulation results. A more realistic prediction of $\mathrm{Li}_{2} \mathrm{O}_{2}$ deposit distribution is obtained, with the peak value of $\mathrm{Li}_{2} \mathrm{O}_{2}$ volume fraction in the middle of the cathode instead of on the top surface, as predicted by previous studies. The interaction between the battery and its surroundings is considered by incorporating the air chamber into the computation domain. The diffusion of solvent vapor and oxygen in this chamber is included. For batteries using volatile solvents such as DMF, increasing the air chamber radius from $5 \mathrm{~cm}$ to 15 $\mathrm{cm}$ would result in a $72 \%$ increase of discharge capacity at the cost of losing a large amount of electrolyte.
\end{abstract}

Keywords: Lithium air battery; Deformed mesh; Modeling; Electrolyte level 


\section{Introduction}

Because of their high theoretical energy density, lithium air (Li-air) batteries, including lithium oxygen $\left(\mathrm{Li}-\mathrm{O}_{2}\right)$ batteries, are considered to be promising candidates as the next generation secondary power supplies for portable devices and electric vehicles. A number of continuum-scale models have been developed to study the detailed charge and mass transport processes inside a Li-air battery. The first reported simulation model for $\mathrm{Li}$-air batteries was by Sandhu et al. in 2007 [1]. Since then, various research groups have incorporated additional details to build more comprehensive models. Albertus et al. [2] was the first to consider solid product precipitation. Wang and Cho [3] developed a model to consider the coverage of reaction surface for different electrode pore shapes. The model by Sahapatsombut et al. [4,5] was the first reported to include the charging process and side reactions. Li and Faghri [6] developed a 2-D model and found that the micro pores closer to the separator/cathode interface were not fully utilized. They proposed a gradient cathode structure to increase specific capacity. Several models [7-9] considered the size distribution function of the pores or carbon particles in the cathode.

All previous studies neglected two important physical phenomena in a Li-air cell. The first is the electrolyte level drop during discharge caused by a decrease in solid phase volume. During discharge, the metallic lithium of the anode is converted to lithium ions, enters the electrolyte and moves to the cathode. In the micro-pores of the cathode, oxygen reduction reaction (ORR) occurs and consumes the lithium ions and electrons. Experimental studies [10] prove that 
insoluble and partially insulating $\mathrm{Li}_{2} \mathrm{O}_{2}$ is the major product of this reaction in non-aqueous electrolyte; therefore the overall reaction can be expressed as:

$$
2 \mathrm{Li}+\mathrm{O}_{2} \rightarrow \mathrm{Li}_{2} \mathrm{O}_{2}
$$

According to the above equation, for each mole of lithium consumed 0.5 moles of $\mathrm{Li}_{2} \mathrm{O}_{2}$ are generated, which translates to $13.0 \mathrm{~cm}^{3}$ of solid consumed and $9.93 \mathrm{~cm}^{3}$ of solid generated. This means a $23.6 \%$ decrease of solid phase volume for each unit volume of lithium anode consumed during discharge. This vacated space must be replaced by the liquid electrolyte and therefore electrolyte level drops during discharge.

Figure 1 shows the structure of a typical $\mathrm{Li}$-air coin cell used in previous experimental studies $[11,12]$. The cell is normally placed on a solid surface with breathing holes facing upward, exposed to an air chamber. To compensate for the volume change, a spring is placed under the anode current collector in the cell. This ensures a tight contact between anode, separator, cathode, and current collectors in the cell. Solid volume decreases during discharge and electrolyte level drops. This effect is noted as an unsolved issue by Yuan et al. [13]. Yoo et al. [14] attempted to address this problem through a 1D model. However, the proposed model assumed a fixed anode and the battery is placed vertically.

The solid phase volume change is not the only factor to cause electrolyte level change. The evaporation of solvent is another phenomenon that is often neglected in modeling works. Most experimental studies on non-aqueous Li-air batteries used volatile solvents such as 1,2dimethoxyethane (DME) and acetonitril (ACN), as indicated by Balaish et al. [15], to achieve a 
high oxygen solubility and diffusivity. Evaporated solvent escapes the battery through the breathing openings and is lost in ambient air. To our best knowledge, no previous modeling studies of the effect of solvent evaporation on cell performance have been reported.

Another often neglected physical phenomenon in Li-air battery models is the interaction of the cell with its surroundings. Lithium air batteries normally interact with their surroundings by consuming or releasing oxygen during the discharge and charge cycles, respectively. However, the computation domain of most existing Li-air battery models is generally bound by the interface of the cathode and ambient air, and assumes a constant dissolved oxygen concentration as the boundary condition. The diffusion of oxygen from the environment into the cell and solvent diffusion into the environment have not been considered in prior studies.

In this paper, the previously neglected physical phenomena are included in our proposed two dimensional transient $\mathrm{Li}$-air coin cell model. These effects on cell performance are examined and discussed based on simulated results. The Arbitrary Lagrangian-Eulerian (ALE) method is employed to describe the deformed computation domain and to track the moving electrolyte level. The air chamber that provides oxygen to the cell is included in the computation domain. The simulation results, both with and without consideration of these effects, are compared and discussed.

\section{Physical Model}

The battery to be modeled has a typical coin cell structure, as shown in Figure 1, and has been widely used in previous experimental studies. Structural parameters of the cell are listed in 
Table 1. The thickness of the cathode is $800 \mu \mathrm{m}$. This value is chosen based on two reasons. First, using a thin cathode means higher percentage of the battery volume is occupied by separator and gas channel, consequently leads to a lower overall capacity. To achieve a competitive capacity, a thicker cathode must be used. Secondly, in most experimental and simulation studies, the cathode thickness is in the range between $500 \mu \mathrm{m}$ to $1 \mathrm{~mm}[4-6,16,17]$. It is assumed that the gas diffusion layer (GDL), cathode, separator and anode lithium metal have the same radius. To reduce the model to two dimensions, a single breathing hole is located at the center of the cathode casing. An axisymmetric assumption is adopted and the total computation domain is shown by the grey area in Figure 2, which contains five sub-domains: the air chamber, GDL, cathode, separator, and anode. The governing equations developed below are used on one or several sub-domains depending on the physical phenomena.

The following assumptions are included to make the computation feasible:

1. $\mathrm{Li}_{2} \mathrm{O}_{2}$ is considered completely insoluble in electrolyte and precipitates on the cathode pore surface immediately upon generation.

2. The reaction shown in eq. (1) is considered. Side reactions are neglected.

3. The charging process is not considered due to the lack of an established understanding of the mechanisms of these reactions.

4. Bulk velocity of the electrolyte is negligible and convection is not considered in mass transport, since the length scale in the cell is in the order of $10^{-3} \mathrm{~m}$ and the time scale of discharge is in the order of $1 \sim 10$ hours. 
5. Thermal effect is assumed to be negligible, including the temperature drop caused by solvent evaporation and consequent change of saturation vapor pressure. This is justifiable due to the small size of the cell and a long time scale of discharge $\left(10^{2}-10^{3}\right.$ minutes).

\subsection{Mass and charge transfer}

The governing equations to describe the mass and charge transport inside the cell follow the common framework used in most previous Li-air continuum-scale models based on concentrated solution and porous electrode theory [18].

Conservation of all species in the electrolyte can be expressed as:

$$
\frac{\partial\left(\varepsilon c_{i}\right)}{\partial t}=-\nabla \cdot N_{i}+r_{i}
$$

where $c_{i}$ is molarity of species $i, \varepsilon$ is local porosity, $N_{i}$ is the molar flux of species $i$, and $r_{i}$ is the species generation rate. According to concentrated solution theory [18], the molar flux of $\mathrm{Li}^{+}$ ions in electrolyte can be expressed as:

$$
N_{\mathrm{Li}}=-D_{e}^{e f f} \nabla c_{\mathrm{Li}}+\frac{i_{2} t_{+}^{0}}{F}
$$

where $D_{e}^{e f f}$ is the effective diffusion coefficient of the salt, $t_{+}^{0}$ is the transference number of lithium ion with respect to the solvent velocity, and $F$ is the Faraday constant. The current density in electrolyte, $\boldsymbol{i}_{2}$, can be expressed as:

$\boldsymbol{i}_{2}=-k_{e}^{e f f} \nabla \phi_{2}-\frac{2 R T k^{e f f}}{F}\left(t_{+}^{0}-1\right)\left(1+\frac{\partial \ln f_{ \pm}}{\partial \ln c_{\mathrm{Li}}}\right) \nabla \ln c_{\mathrm{Li}}$ 
where $k_{e}^{e f f}$ is the effective ionic conductivity of the electrolyte, $f_{ \pm}$is the salt activity coefficient, and $\left(1+\frac{\partial \ln f_{ \pm}}{\partial \ln c_{\mathrm{Li}}}\right)$ is the thermodynamic factor [19]. In this model, the electrolyte conductivity is assumed to be a constant because of lack of data. This needs to be addressed in future studies because with the evaporation of solvent, electrolyte concentration change might be high enough to have a significant effect on conductivity and salt diffusivity.

To simplify the equations, the diffusion conductivity, $k_{\mathrm{D}}$, is defined [20]:

$k_{D}=\frac{2 R T k^{e f f}}{F}\left(t_{+}^{0}-1\right)\left(1+\frac{\partial \ln f_{ \pm}}{\partial \ln c_{\mathrm{Li}}}\right)$

Combining eqs. (2) - (5) yields the following equation for lithium ion transport:

$\varepsilon \frac{\partial c_{\mathrm{Li}}}{\partial t}+\nabla \cdot\left(-D_{e}^{e f f} \nabla c_{\mathrm{Li}}\right)=r_{\mathrm{Li}}-\nabla \cdot\left(\frac{\boldsymbol{i}_{2} t_{+}}{F}\right)$

Dissolved oxygen is transported in the electrolyte by diffusion and therefore its molar flux can be expressed as [21]:

$$
N_{\mathrm{O}_{2}}=-D_{\mathrm{O}_{2}}^{e f f} \nabla c_{\mathrm{O}_{2}}
$$

Combining eqs. (2) and (7) leads to the following equation for dissolved oxygen transport:

$\varepsilon \frac{\partial c_{\mathrm{O}_{2}}}{\partial t}+\nabla \cdot\left(-D_{\mathrm{O}_{2}}^{e f f} \nabla c_{\mathrm{O}_{2}}\right)=r_{\mathrm{O}_{2}}$

The generation rates of the lithium ion, $r_{\mathrm{Li}}$, in eq. (6), and oxygen, $r_{\mathrm{O}_{2}}$, in eq. (8), can be related to the local transfer current density between electrolyte and electrode, $j_{\mathrm{R}}$, as:

$r_{\mathrm{Li}}=\frac{A_{E D} j_{\mathrm{R}}}{F}$

and 
$r_{\mathrm{O}_{2}}=\frac{A_{E D} j_{\mathrm{R}}}{2 F}$

where $A_{\mathrm{ED}}$ is the specific reaction surface. The product $A_{\mathrm{ED}} j_{\mathrm{R}}$ is the cathode volumetric current density which is the direct indicator of local electrochemical reaction rate.

To maintain charge balance, the divergence of electrolyte current density should be equal to the volumetric current density:

$\nabla \cdot \boldsymbol{i}_{2}=A_{E D} j_{R}$

Combining eqs. (4) and (11) results in the following equation for electrolyte potential:

$$
\nabla \cdot\left(-k^{e f f} \nabla \phi_{2}\right)=\nabla \cdot\left(\frac{k_{D}}{c_{\mathrm{Li}}} \nabla c_{\mathrm{Li}}\right)+A_{E D} j_{R}
$$

The governing equations for $c_{\mathrm{Li}}, c_{\mathrm{O}_{2}}$, and $\phi_{2}$ (eqs. (6), (8), and (12)) are computed over a set of deforming meshes covering the subdomains of the cathode and separator shown in Figure 2. The moving boundary of the deforming mesh reflects the drop in electrolyte level during discharge.

The current balance between the electrolyte and cathode solid phase indicates that:

$\nabla \cdot i_{1}+\nabla \cdot i_{2}=0$

where $i_{1}$ is the current density in the cathode solid phase, which can be expressed simply by Ohm's law:

$i_{1 c}=-k_{c}^{e f f} \nabla \phi_{1 c}$

where $k_{c}^{e f f}$ is the electronic conductivity of the cathode solid phase. Therefore, cathode electric potential can be obtained from eqs. (11), (13), and (14) as: 
$\nabla \cdot\left(-k_{c}^{e f f} \nabla \phi_{1 c}\right)=-A_{E D} j_{\mathrm{R}}$

which is computed on a set of fixed meshes covering the GDL and cathode subdomains, shown in Figure 2.

Oxygen and solvent vapor transport in the GDL and air chamber are controlled by diffusion according to Fick's law:

$\varepsilon \frac{\partial c_{o a}}{\partial t}+\nabla \cdot\left(-D_{o a}^{e f f} \nabla c_{o a}\right)=0$

$\varepsilon \frac{\partial c_{s a}}{\partial t}+\nabla \cdot\left(-D_{s a}^{e f f} \nabla c_{s a}\right)=0$

where $c_{o a}$ and $c_{s a}$ are the concentrations of oxygen and solvent vapor in air, respectively; $D_{o a}^{e f f}$ and $D_{s a}^{e f f}$ are the effective diffusion coefficients of oxygen and solvent vapor in air, respectively. Equations (16) and (17) are solved on the subdomains of the GDL and air chamber shown in Figure 2 .

The effective parameters used in the above equations, including $D_{\mathrm{Li}}^{\text {eff }}, k^{\text {eff }}, D_{\mathrm{O}_{2}}^{\text {eff }}, D_{\mathrm{oa}}^{\text {eff }}$, and $D_{\text {sa }}^{\text {eff }}$, can be calculated through the Bruggeman correlation [22]:

$\Phi^{e f f}=\Phi \varepsilon^{\beta}$

where $\Phi$ can be $D_{\mathrm{Li}}, k_{e}, D_{\mathrm{O}_{2}}, D_{\mathrm{oa}}$, and $D_{\mathrm{sa}}$. Similarly, $k_{\mathrm{c}}^{\text {eff }}$ can be expressed as:

$k_{c}^{e f f}=k_{c}\left(1-\varepsilon_{0}-\varepsilon_{\mathrm{b}}\right)^{\beta}$

where $k_{c}$ is the electron conductivity in the carbon phase of the cathode and $\varepsilon_{\mathrm{b}}$ is the volume fraction of electrode binder. The Bruggeman coefficient, $\beta$, is assumed to be a constant 1.5 [23]. 
Due to the deposition of the insoluble reaction product $\mathrm{Li}_{2} \mathrm{O}_{2}$, porosity in the cathode is a function of both location and time during the discharge process. It can be related to the volume fraction of precipitated product $\varepsilon_{\mathrm{s}}$, and original porosity $\varepsilon_{0}$, through:

$\varepsilon=\varepsilon_{0}-\varepsilon_{\mathrm{s}}$

The mass conservation of discharge product, $\mathrm{Li}_{2} \mathrm{O}_{2}$, is used to obtain $\varepsilon_{\mathrm{s}}$ :

$\frac{\partial \varepsilon_{\mathrm{s}}}{\partial t}=-\frac{M_{\mathrm{Li}_{2} \mathrm{O}_{2}}}{2 \rho_{\mathrm{Li}_{2} \mathrm{O}_{2}} F} A_{E D} j_{\mathrm{R}}$

where $M_{\mathrm{Li}_{2} \mathrm{O}_{2}}$ is the molecular weight of $\mathrm{Li}_{2} \mathrm{O}_{2}$, and $\rho_{\mathrm{Li}_{2} \mathrm{O}_{2}}$ is the density of $\mathrm{Li}_{2} \mathrm{O}_{2}$. The transfer current density $j_{R}$, is to be determined by reaction kinetics. Equation (21) is computed on a set of fixed meshes covering the subdomain of the cathode shown in Figure 2.

The driving force for the cathode reaction is the local activation overpotential $\eta_{c}$, which can be defined as:

$\eta_{\mathrm{c}}=\phi_{1 c}-\phi_{2}-\Delta \phi_{\mathrm{Li}_{2} \mathrm{O}_{2}}-E_{\mathrm{c}}^{0}$

where $\Delta \phi_{\mathrm{Li}_{2} \mathrm{O}_{2}}$ is the voltage drop over the $\mathrm{Li}_{2} \mathrm{O}_{2}$ film and $E_{\mathrm{c}}{ }^{0}$ is the cathode theoretical potential. The voltage drop across the $\mathrm{Li}_{2} \mathrm{O}_{2}$ film is calculated by Ohm's law [4]:

$\Delta \phi_{\mathrm{Li}_{2} \mathrm{O}_{2}}=j_{\mathrm{R}} R_{\mathrm{Li}_{2} \mathrm{O}_{2}} \varepsilon_{\mathrm{s}}$

where $R_{\mathrm{Li}_{2} \mathrm{O}_{2}}$ is the electrical resistivity across the $\mathrm{Li}_{2} \mathrm{O}_{2}$ film.

The Tafel equation [24] is used to express the cathode reaction kinetics:

$j_{\mathrm{R}}=-k_{\mathrm{R}}\left(\frac{c_{\mathrm{Li}}}{c_{\mathrm{Li}}^{\text {ref }}}\right)^{2}\left(\frac{c_{\mathrm{O}_{2}}}{c_{\mathrm{O}_{2}}^{\text {ref }}}\right) \exp \left(-\frac{\alpha_{\mathrm{c}} F}{R T} \eta_{\mathrm{c}}\right)$ 
where $k_{\mathrm{R}}$ is the rate constant for the cathode reaction, and $\alpha_{\mathrm{c}}$ is the transfer coefficient, equal to 0.5. Reference concentrations $c_{\mathrm{Li}}^{\text {ref }}$ and $c_{\mathrm{O}_{2}}^{\text {ref }}$ are set to be $1 \mathrm{M}$ and the saturated oxygen concentration, $c_{\mathrm{O}_{2} \text {,sat }}$, respectively.

Anode reaction kinetics is described by the Butler-Volmer equation [24]:

$$
j_{\mathrm{a}}=i_{0}\left[\exp \left(\frac{\left(1-\alpha_{a}\right) F}{R T} \eta_{\mathrm{a}}\right)-\exp \left(-\frac{\alpha_{a} F}{R T} \eta_{\mathrm{a}}\right)\right]
$$

where $j_{\mathrm{a}}$ is the transfer current density at the anode/separator interface (denoted as (4) in Figure 2 ), and $i_{0}$ is the exchange current density for the anode. The anode activation overpotential, $\eta_{\mathrm{a}}$, is defined as:

$\eta_{\mathrm{a}}=\phi_{1 a}-\phi_{2}-E_{\mathrm{a}}^{0}$

where $\phi_{1 a}$ is the anode electrode potential and $E_{a}{ }^{0}$ is the anode theoretical potential, $0 \mathrm{~V}$. The anode electrode potential is governed by Ohm's law:

$\nabla \cdot\left(-k_{\mathrm{Li}} \nabla \phi_{1 a}\right)=0$

where $k_{\mathrm{Li}}$ is the conductivity of lithium metal. This governing equation is computed on the moving mesh set covering the subdomain of the anode shown in Figure 2. The moving mesh reflects the shrinking of the anode lithium foil during discharge.

The effect of reaction area loss due to $\mathrm{Li}_{2} \mathrm{O}_{2}$ deposition is described by the following empirical relation [5]:

$$
A_{\mathrm{ED}}=A_{\mathrm{ED}, 0}\left[1-\left(\frac{\varepsilon_{\mathrm{s}}}{\varepsilon_{0}}\right)^{z}\right]
$$


where $A_{\mathrm{ED}, 0}$ is the original specific area and the value for $z$ is set to 0.5 . In summary, there are eight unknowns in the model described above: electrolyte concentration $c_{\mathrm{Li}}$, dissolved oxygen concentration $c_{\mathrm{O}_{2}}$, electrolyte potential $\phi_{2}$, cathode electrode potential, $\phi_{1 c}$, oxygen gas concentration $c_{o a}$, solvent vapor concentration $c_{s a}$, anode electrode potential $\phi_{1 a}$ and deposit layer volume fraction $\varepsilon_{\mathrm{s}}$. They are described by seven partial differential equations (6), (8), (12), (15), (16), (17), (27), and one ordinary differential equation (21).

\subsection{Moving boundaries}

As discussed in section 1, the velocity of the moving electrolyte level (1) in Figure 2) consists of two parts:

$V_{1}=-\left(V_{1 v}+V_{1 e}\right)$

where $V_{1 v}$ is the velocity due to the liquid replacing the vanishing solid phase, and $V_{1 e}$ is caused by solvent evaporation. The negative sign is due to the surface moving in the negative direction of $z \cdot V_{1 v}$ is related to discharge current density $I$ :

$V_{1 v}=\frac{I}{\varepsilon_{1} F}\left(\frac{M_{\mathrm{Li}}}{\rho_{\mathrm{Li}}}-\frac{M_{\mathrm{Li}_{2} \mathrm{O}_{2}}}{2 \rho_{\mathrm{Li}_{2} \mathrm{O}_{2}}}\right)$

where $\varepsilon_{1}$ is the average porosity of the cathode at the electrolyte level, and $M$ and $\rho$ are the molecular weight and density, respectively. The subscripts $\mathrm{Li}$ and $\mathrm{Li}_{2} \mathrm{O}_{2}$ denote lithium and deposited lithium peroxide, respectively. $V_{l e}$ is related to the molar flux of solvent vapor $N_{\text {sv }}$ on the electrolyte surface: 
$V_{1 e}=\frac{\int_{A e s} N_{s v} d A}{A_{e s}} \frac{M_{s v}}{\varepsilon_{1} \rho_{s}}$

where $A_{\text {es }}$ denotes the area of the electrolyte surface and the subscript $s v$ denotes solvent. The molar flux of evaporated solvent $N_{\mathrm{sv}}$ is calculated by:

$N_{s v}=-\left.D_{s v} \frac{\partial c_{s v}}{\partial z}\right|_{A_{c s}}$

where $D_{\mathrm{sv}}$ is the diffusion coefficient of solvent vapor in air and $c_{\mathrm{sv}}$ is the concentration of solvent vapor in air.

The bottom of the anode lithium foil (2) in Figure 2), moves upward during discharge and its velocity is:

$V_{2}=\frac{M_{L i}}{F \rho_{L i}} I$

This velocity is expected to be constant since the discharge is under constant current.

\subsection{Boundary conditions}

At the anode/separator interface (3) in Figure 2), the electrolyte current density is equal to the discharge current density and the molar flux of dissolved oxygen is zero. At the separator/cathode interface (4) in Figure 2), the cathode electrode current is zero. At the cathode/GDL interface (1) in Figure 2), the electrolyte current and $\mathrm{Li}^{+}$molar flux are both equal to zero, and the concentration of the dissolved oxygen is determined based on Henry's law:

$c_{\mathrm{O}_{2}}=\frac{c_{o a}}{c_{0}} c_{\mathrm{O}_{2}, s a t}$ 
where $c_{0}$ is the total molar concentration of ideal gas at 1 bar and $25{ }^{\circ} \mathrm{C}$ and $c_{\mathrm{O}_{2} \text {,sat }}$ is the solubility of oxygen in the electrolyte. Concentration of solvent vapor at this boundary is determined by the ideal gas law and its vapor saturation pressure $p_{s a}$ :

$c_{s a}=\frac{p_{s a}}{p_{0}} c_{0}$

where $p_{0}$ is 1 bar. The effect of lithium salt on solvent vapor pressure is neglected. The molar flux of oxygen and solvent vapor are zero at the air chamber wall (8) in Figure 2). The current density is equal to the discharge current density divided by the open ratio at the cathode casing (6) in Figure 2). The thickness of the cathode casing is neglected in the model. It should be noted that eqs. (34) and (35) are derived based on the assumption that pressure in the air chamber is constant. This is considered to be a reasonable assumption because the influx of evaporated DMF in the air chamber would cause an increase in pressure of less than $0.52 \%$ (516 Pa vapor pressure vs. 1 bar initial air chamber pressure) even if oxygen consumption is not considered, which conversely decreases pressure. The governing equations, boundary conditions and initial conditions are summarized in Table 2.

At the start of discharge, the air chamber and GDL are filled with air at 1 bar and with 0 pa solvent vapor. The electrolyte and dissolved oxygen concentrations are all uniform, at the values of $1 \mathrm{M}$ and the saturated value $c_{\mathrm{O}_{2} \text {,sat }}$, respectively. The cathode, separator, anode and spring are all immersed in electrolyte. 


\subsection{Computational methodology}

The above governing equations are discretized and solved using the finite element method in COMSOL Multiphysics 4.4. Two sets of meshes are used. The first mesh set has 3643 elements, and it covers all the subdomains shown in Figure 2. The air chamber domain is discretized using a free triangular mesh while the other domains are discretized using a mapped rectangular mesh. In this mesh set, boundaries (1) and (2) can translate along the $z$ direction, therefore the GDL, cathode, and anode sub-domains deform during the time-dependent calculation. The velocities of the moving boundaries are defined in eqs. (29) - (31) and (33). The ALE method [25] is used to enable geometry deformation. The second mesh set (4000 elements) is fixed and includes the cathode and GDL. Governing equations for $\varepsilon_{\mathrm{s}}$ and $\phi_{\mathrm{lc}}$ are solved on this mesh set. Cathode specific surface area $A_{\mathrm{ED}}$ and transfer current density $j_{\mathrm{R}}$ are mapped from the deformed mesh onto this fixed mesh. The resulting values of $\varepsilon_{\mathrm{s}}$ and $\phi_{1 c}$ are then mapped back to the deformed mesh through linear projection on a spatial frame. A time-dependent solver is employed to solve all the governing equations. A constant discharge current density $I$ is imposed and the cell voltage is obtained through the difference between the cathode electrode potential at boundary (6) and the anode electrode potential at boundary (2) for each time step. The maximum time step ranges between 10 and 100 seconds depending on the discharge current density; higher discharge current densities require a smaller time step. All results are proven to be mesh independent and time step independent. 
Two different electrolytes are used in the calculations, including dimethyl formamide (DMF) and tetraethylene glycol dimethyl ether (TEGDME). These are chosen as solvents because of their opposing high and low vapor pressures, respectively. TEGDME is a widely used low vapor pressure organic solvent $(\sim 1 \mathrm{~Pa})$ in experimental studies, while DMF has a fairly high vapor pressure (516 $\mathrm{Pa}$ at standard condition). The associated properties of both solvents are listed in Table 3. The diffusion coefficients of the solvent vapor in air are calculated using the FSG/LaBas method [26]. Oxygen diffusivities in the electrolyte are estimated through the Stokes-Einstein relation based on solvent viscosity [27]. Other parameters used in the calculation are provided in Table 4.

\section{Results and discussion}

\subsection{Model calibration}

The model is calibrated by comparing the simulated discharge curves with the experimental results of Read [16], in which PC:DME was used as electrolyte solvent. The evaporation of solvent is not considered in this comparison because of the lack of vapor pressure data for a PC:DME mixture. The open ratio of the cathode casing was assumed to be $100 \%$ and the air chamber was assumed to be filled with pure oxygen initially. There are two purposes of this comparison. Firstly, the cathode rate constant, $k_{\mathrm{R}}$, is obtained by matching the discharge curves to experimental results [16]. Secondly, it shows that the model is able to predict the key discharge characteristics of a Li-air battery: sudden death at the end and lower capacity at higher discharge current. 


\subsection{Tracking the electrolyte level}

Figure 4 indicates the position ( $z$ value) of the electrolyte level and anode/spring interface for two different electrolytes. Figure 4(a) shows the case with the DMF based electrolyte while Figure 4(b) shows the case with TEGDME based electrolyte. Discharge current densities for both cases are $0.5 \mathrm{~A} \mathrm{~m}^{-2}$ and the cathode opening radius is $0.5 \mathrm{~mm}$. The upper solid line represents the drop in electrolyte level while the lower solid line depicts the rise of the bottom of the anode lithium foil. The anode bottom surface rises linearly over time due to a constant discharge current, and therefore $V_{2}$ remains constant according to eq. (33). The dashed line separates the displacement of electrolyte surface into two parts for both solvents: The upper region is caused by solvent evaporation while the lower area is attributed to solid phase volume decrease. Solvent evaporation occurs quickly and fills the air chamber in several hundred minutes. Solvent evaporation then gradually slows when the partial pressure of solvent vapor in the chamber approaches its saturated value. The electrolyte level displacement caused by the solvent evaporation correspondingly stops. The distance between the dashed line and the lower solid line represents the electrolyte level drop caused by the solid phase volume decrease. The electrolyte level drops faster towards the end of discharge because of a higher $V_{1 \mathrm{v}}$. The only non-constant parameter that influences $V_{1 \mathrm{v}}$ is the average porosity $\varepsilon_{1}$, as noted in eq. (30), which changes due to the increased $\mathrm{Li}_{2} \mathrm{O}_{2}$ deposition. There are two features of significance when comparing Figure 4(a) and (b). The first is that DMF evaporation causes a much larger electrolyte level drop due to its higher vapor pressure. $V_{1 \mathrm{e}}$ is several times larger for the DMF based cell than for the 
TEGDME based cell. Secondly, the discharge time of the DMF based cell is much greater than that of TEGDME, due to a much higher oxygen diffusivity in DMF (see Table 3).

\subsection{Effect of electrolyte level change}

It seems intuitive that a model accounting for electrolyte level change would predict a lower discharge capacity because of the loss of electrolyte. However, the predicted result indicates the opposite trend. Figure 5 compares the discharge curves of models with and without consideration of electrolyte level drop during discharge. The present model predicts a $22.5 \%$ higher discharge capacity for a DMF based cell at $5 \mathrm{~A} \mathrm{~m}^{-2}$ and a $14.9 \%$ higher discharge capacity for a TEGDME based cell at $0.5 \mathrm{~A} \mathrm{~m}^{-2}$. Therefore, neglect of electrolyte level drop during discharge would result in an underestimation of cell discharge capacity. To better explain this conclusion, the effects of electrolyte level drop need to be examined.

There are three primary effects of electrolyte level drop on Li-air battery operation. The first is less cathode soaked in electrolyte and consequently less reaction surface. A higher overpotential must then be maintained for the required current output, which yields a smaller discharge time and capacity. However, an inspection of the distribution of reaction rate reveals that the electrochemical reaction takes place only in a small section of the cathode adjacent to the electrolyte surface, which means only a small percentage of the cathode reaction surface is used. Therefore, the loss of reaction surface only has a small influence on discharge capacity. 
The second effect caused by electrolyte level drop is a decrease in electrolyte thickness, and consequent lower ion migration resistance and higher discharge capacity. The overpotential caused by the finite electrolyte conductivity can be approximated as:

$\eta_{2}=\frac{I\left(h_{\text {cath }} / 2+h_{\text {sep }}\right)}{k_{e}}$

where $h_{\text {cath }}$ is the thickness of the electrolyte in the cathode (which decreases) and $h_{\text {sep }}$ is the thickness of the separator. The electrolyte level drops $0.17 \mathrm{~mm}$ for a DMF based cell and 0.013 $\mathrm{mm}$ for a TEGDME based cell at the end of discharge, when the discharge current density is 0.5 A $\mathrm{m}^{-2}$. This corresponds to a $0.03 \mathrm{mV}$ and $0.05 \mathrm{mV}$ decrease of $\eta_{2}$, for DMF and TEGDME based cells, respectively. These value are negligible compared to other overpotentials, such as that for reaction activation. The decreased ion migration resistance caused by electrolyte level drop is also relatively insignificant.

Compared to the above two phenomena, the third effect caused by electrolyte level drop is significant based on the model prediction. Figure 6(a) illustrates the $\mathrm{Li}_{2} \mathrm{O}_{2}$ deposition on the cathode solid phase surface with a constant electrolyte level during discharge. The electrolyte level remains unchanged during discharge. The reaction rate and $\mathrm{Li}_{2} \mathrm{O}_{2}$ generation rate are at their highest because the oxygen concentration at this surface is also at its highest at any location in the cathode. This leads to the thickest deposition layer of $\mathrm{Li}_{2} \mathrm{O}_{2}$ at the cathode/GDL interface. Most existing modeling studies showed a similar $\mathrm{Li}_{2} \mathrm{O}_{2}$ distribution profile $[5,8,17]$. However, if electrolyte level drop is considered, this distribution profile is no longer valid. Figure 6(b) shows 
the electrolyte level at various times during discharge. As the electrolyte level drops, the position with maximum reaction rate and $\mathrm{Li}_{2} \mathrm{O}_{2}$ deposition drops accordingly. This leads to a final $\mathrm{Li}_{2} \mathrm{O}_{2}$ volume fraction $\left(\varepsilon_{\mathrm{s}}\right)$ distribution curve that peaks where the electrolyte surface is located at the end of the discharge. At each time interval, the maximum reaction rate area is lowered slightly. This alleviates electrode blocking and predicts a better electrode utilization than for a constant electrolyte level. Figure 7 shows the predicted final $\varepsilon_{s}$ distribution with and without consideration of electrolyte level change. The results match with the qualitative analysis of Figure 6. An integration of $\varepsilon_{s}$ over the entire cathode volume shows that without considering electrolyte drop, $22.0 \%$ of the cathode pore volume is used at the end of discharge while inclusion of the electrolyte level drop increases this value to $24.3 \%$. This agrees with the prediction of increased cathode specific capacity.

\subsection{Effect of air chamber size}

Solvent evaporation causes a large part of electrolyte level drop for a DMF based cell, as evidenced by Figure 4(a). The size of the air chamber directly affects the amount of solvent evaporation. The larger the chamber, the more solvent vapor can be accommodated before saturation, which affects cell discharge capacity. The chamber size was chosen to ensure that less than $5 \%$ of the oxygen original stored in the chamber was used during discharge, and therefore during discharge the pressure in the chamber keeps at a constant pressure. Figure 8 shows the discharge curves of a cell using DMF based electrolyte undergoing a $0.5 \mathrm{~A} \mathrm{~m}^{-2}$ discharge. It reveals that cathode specific capacity increases $72 \%$ from $530 \mathrm{mAh} \mathrm{g}^{-1}$ to $910 \mathrm{mAh} \mathrm{g}^{-1}$ when the 
air chamber radius is increased from $5 \mathrm{~cm}$ to $15 \mathrm{~cm}$. However, with a $15 \mathrm{~cm}$ radius, $33.8 \%$ of the cathode is exposed to air instead of immersed in electrolyte at the end of discharge, about half of which is caused by solvent evaporation. In comparison, for a cell with a $5 \mathrm{~cm}$ air chamber radius, only $8.2 \%$ of the cathode is exposed to air at the end of discharge. The same calculation was done for a TEGDME based cell, with the result showing that air chamber size has negligible effect on cell performance because of a very low vapor pressure. The current model only considers the first discharge of the battery. The charging process needs to be included in future models to study the effect of chamber size on cycling performance of the battery. It should also be noted that if it is assumed that the air chamber is already saturated with solvent vapor at the start of the discharge, the effect of chamber size on electrolyte level change would be negligible.

\section{Conclusions}

In a non-aqueous Li-air battery, the electrolyte level drops during discharge. This is caused by two phenomena, the decrease of the solid phase volume and electrolyte solvent evaporation. A 2-D Li-air coin cell physical model is developed with mesh deformation to track the electrolyte level during discharge. The position of electrolyte surface and its velocity are calculated. The diffusion of solvent vapor in the cell GDL and air chamber are also considered. The following conclusions are made based on the simulation results of a single cell with the cathode thickness of $800 \mu \mathrm{m}$ :

1. The electrolyte surface velocity caused by solvent evaporation is at its highest at the beginning of discharge and then decreases to zero when the air chamber is saturated with solvent 
vapor. The surface velocity imposed by solid volume decrease gradually rises because of increased $\mathrm{Li}_{2} \mathrm{O}_{2}$ deposition and decreased porosity.

2. A Li-air battery model would predict a higher cathode specific discharge capacity by including the effect of electrolyte level drop. In the cases studied in this paper, the increase can be up to $22.5 \%$ for a cell using DMF based electrolyte and $14.9 \%$ for a cell using TEGDME based electrolyte.

3. The proposed model describes a different $\mathrm{Li}_{2} \mathrm{O}_{2}$ distribution profile than those shown in previous studies. When electrolyte level drops during discharge, the position of the greatest $\mathrm{Li}_{2} \mathrm{O}_{2}$ deposition gradually moves with the surface. The final distribution of the $\mathrm{Li}_{2} \mathrm{O}_{2}$ volume fraction shows a peak in the middle of the cathode.

4. The air chamber has significant influence on discharge capacity for cells that use DMF based electrolyte. The discharge capacity increased by $72 \%$ when the radius of the chamber increased from $5 \mathrm{~cm}$ to $15 \mathrm{~cm}$. This is accompanied by a large amount of solvent loss. At the end of discharge, $33.8 \%$ of the cathode volume is exposed in air instead of immersed in electrolyte.

\section{Acknowledgement}

The financial support from the National Science Foundation (Contract No. CBET-1343187) is gratefully acknowledged. 


\section{Nomenclature}
A specific area $\left(\mathrm{m}^{-1}\right)$
c concentration $\left(\mathrm{mol} \mathrm{m}^{-3}\right)$
$D \quad$ diffusivity $\left(\mathrm{m}^{2} \mathrm{~s}^{-1}\right)$
$d \quad$ displacement (m)
$E^{0} \quad$ thermodynamic equilibrium voltage (V)
F $\quad$ Faraday constant $\left(96,485 \mathrm{C} \mathrm{mol}^{-1}\right)$
$f_{ \pm} \quad$ Salt activity coefficient
I discharge current density $\left(\mathrm{A} \mathrm{m}^{-2}\right)$
$i \quad$ current density $\left(\mathrm{A} \mathrm{m}^{-2}\right)$
$j \quad$ transfer current density between electrode and electrolyte $\left(\mathrm{A} \mathrm{m}^{-2}\right)$
$k_{e} \quad$ ionic conductivity $\left(\mathrm{S} \mathrm{m}^{-1}\right)$
$k_{c} \quad$ electron conductivity in carbon phase of electrode $\left(\mathrm{S} \mathrm{m}^{-1}\right)$
$k_{D} \quad$ diffusion conductivity $\left(\mathrm{A} \mathrm{m}^{-1}\right)$
$k_{\mathrm{R}} \quad$ reaction rate constant $\left(\mathrm{A} \mathrm{m}^{-2}\right)$
$M \quad$ molecular weight $\left(\mathrm{kg} \mathrm{mol}^{-1}\right)$
$N \quad$ molar flux $\left(\mathrm{mol} \mathrm{m} \mathrm{m}^{-2} \mathrm{~s}^{-1}\right)$
$O_{r} \quad$ cathode casing open ratio
$p \quad$ pressure $(\mathrm{Pa})$ 


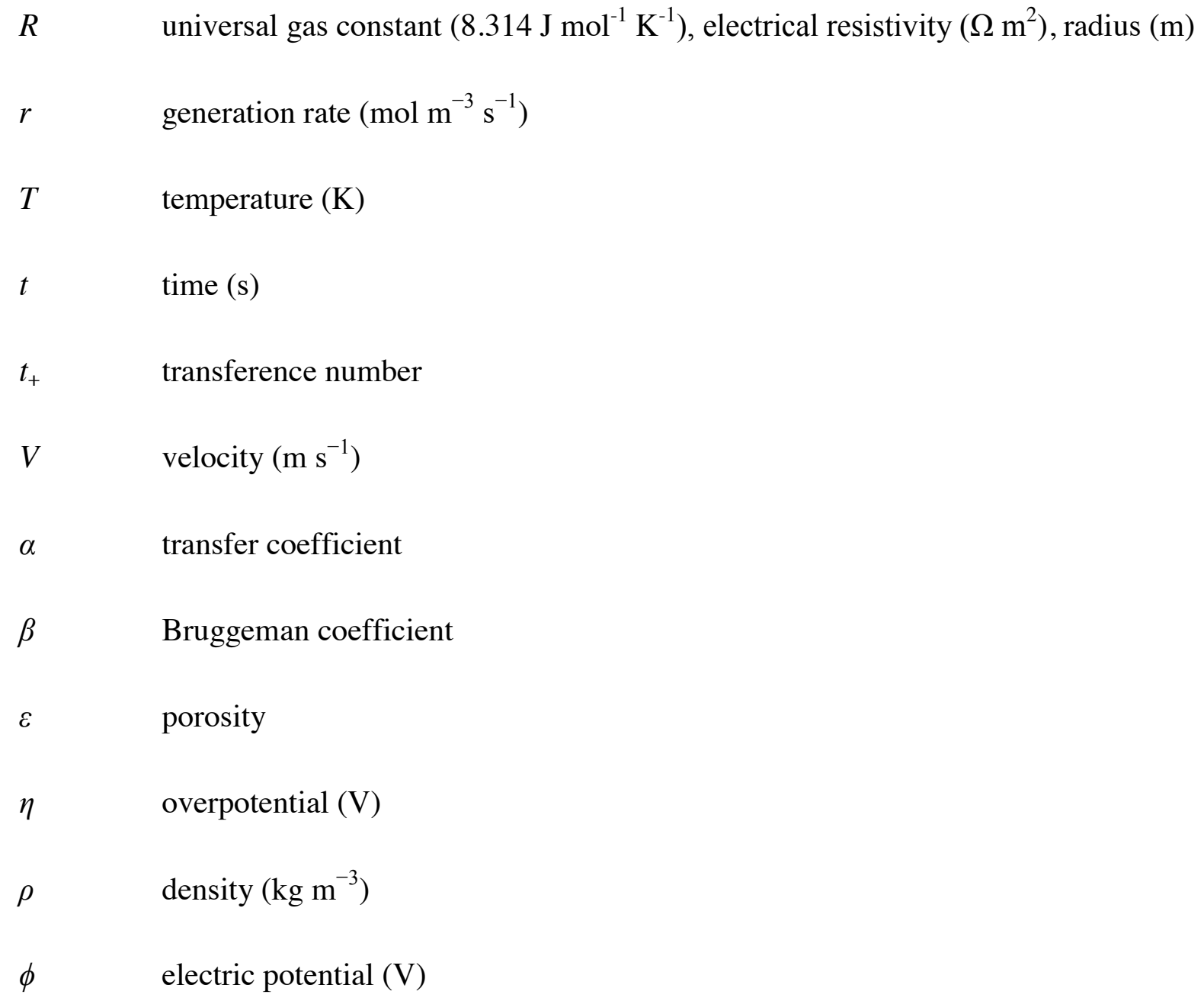

\section{Superscripts and Subscripts}

$1 \quad$ electrode solid phase

2 electrolyte phase

$\begin{array}{ll}a & \text { anode } \\ c & \text { cathode } \\ \text { eff } & \text { effective value } \\ \text { oa } & \text { oxygen in air }\end{array}$




\section{References}

[1] S.S. Sandhu, J.P. Fellner, G.W. Brutchen, Diffusion-limited model for a lithium/air battery with an organic electrolyte, J. Power Sources. 164 (2007) 365-371. doi:10.1016/j.jpowsour.2006.09.099.

[2] P. Albertus, G. Girishkumar, B. McCloskey, R.S. Sánchez-Carrera, B. Kozinsky, J. Christensen, et al., Identifying Capacity Limitations in the Li/Oxygen Battery Using Experiments and Modeling, J. Electrochem. Soc. 158 (2011) A343-A351. doi:10.1149/1.3527055.

[3] Y. Wang, S.C. Cho, Analysis of Air Cathode Perfomance for Lithium-Air Batteries, J. Electrochem. Soc. 160 (2013) A1847-A1855. doi:10.1149/2.092310jes.

[4] U. Sahapatsombut, H. Cheng, K. Scott, Modelling of electrolyte degradation and cycling behaviour in a lithium-air battery, J. Power Sources. 243 (2013) 409-418. doi:10.1016/j.jpowsour.2013.06.043.

[5] U. Sahapatsombut, H. Cheng, K. Scott, Modelling the micro-macro homogeneous cycling behaviour of a lithium-air battery, J. Power Sources. 227 (2013) 243-253. doi:10.1016/j.jpowsour.2012.11.053.

[6] X. Li, A. Faghri, Optimization of the cathode structure of lithium-air batteries based on a two-dimensional, transient, non-isothermal model, J. Electrochem. Soc. 159 (2012) A1747-A1754. doi:10.1149/2.043210jes.

[7] A.A. Franco, K.-H. Xue, Carbon-based electrodes for lithium air batteries: Scientific and technological challenges from a modeling perspective, ECS J. Solid State Sci. Technol. 2 (2013) M3084-M3100. doi:10.1149/2.012310jss.

[8] K.-H. Xue, T.-K. Nguyen, A.A. Franco, Impact of the Cathode Microstructure on the Discharge Performance of Lithium Air Batteries: A Multiscale Model, J. Electrochem. Soc. 161 (2014) E3028-E3035. doi:10.1149/2.002408jes.

[9] X.J. Chen, V. V. Bevara, P. Andrei, M. Hendrickson, E.J. Plichta, J.P. Zheng, Combined Effects of Oxygen Diffusion and Electronic Resistance in Li-Air Batteries with Carbon Nanofiber Cathodes, J. Electrochem. Soc. 161 (2014) A1877-A1883. doi:10.1149/2.0721412jes. 
[10] C.O. Laoire, S. Mukerjee, K.M. Abraham, E.J. Plichta, M.A. Hendrickson, Influence of Nonaqueous Solvents on the Electrochemistry of Oxygen in the Rechargeable Lithium-Air Battery, J. Phys. Chem. C. 114 (2010) 9178-9186. doi:10.1021/jp102019y.

[11] X. Zhang, L. Hua, E. Yang, Z. An, J. Chen, X. Chen, et al., A simple method of making a Li-air battery with longevity, Int. J. Electrochem. Sci. 7 (2012) 10562-10569.

[12] G. a Elia, J. Hassoun, W.-J. Kwak, Y.-K. Sun, B. Scrosati, F. Mueller, et al., An advanced lithium-air battery exploiting an ionic liquid-based electrolyte., Nano Lett. 14 (2014) 6572-7. doi:10.1021/n15031985.

[13] J. Yuan, J.-S. Yu, B. Sundén, Review on mechanisms and continuum models of multiphase transport phenomena in porous structures of non-aqueous Li-Air batteries, J. Power Sources. 278 (2015) 352-369. doi:10.1016/j.jpowsour.2014.12.078.

[14] K. Yoo, S. Banerjee, P. Dutta, Modeling of volume change phenomena in a Li-air battery, J. Power Sources. 258 (2014) 340-350. doi:10.1016/j.jpowsour.2014.02.044.

[15] M. Balaish, A. Kraytsberg, Y. Ein-Eli, A critical review on lithium-air battery electrolytes., Phys. Chem. Chem. Phys. 16 (2014) 2801-22. doi:10.1039/c3cp54165g.

[16] J. Read, Characterization of the Lithium/Oxygen Organic Electrolyte Battery, J. Electrochem. Soc. 149 (2002) A1190-A1195. doi:10.1149/1.1498256.

[17] C.Y. Jung, T.S. Zhao, L. An, Modeling of lithium-oxygen batteries with the discharge product treated as a discontinuous deposit layer, J. Power Sources. 273 (2015) 440-447. doi:10.1016/j.jpowsour.2014.09.103.

[18] J. Newman, K.E. Thomas-Alyea, Electrochemical Systems, 3rd ed., John Wiley \& Sons, Hoboken, NJ, 2004.

[19] A. Nyman, M. Behm, G. Lindbergh, Electrochemical characterisation and modelling of the mass transport phenomena in $\mathrm{LiPF}_{6}-\mathrm{EC}-\mathrm{EMC}$ electrolyte, Electrochim. Acta. 53 (2008) 6356-6365. doi:10.1016/j.electacta.2008.04.023.

[20] P. Andrei, J.P. Zheng, M. Hendrickson, E.J. Plichta, Modeling of Li-air batteries with dual electrolyte, J. Electrochem. Soc. 159 (2012) A770-A780. doi:10.1149/2.010206jes.

[21] A. Faghri, Y. Zhang, Transport Phenomena in Multiphase Systems, Academic Press, 2006. doi:10.1016/0167-2738(81)90101-6. 
[22] W. Lai, F. Ciucci, Mathematical modeling of porous battery electrodes-Revisit of Newman's model, Electrochim. Acta. $56 \quad$ (2011) 4369-4377. doi:10.1016/j.electacta.2011.01.012.

[23] H. Bahrami, A. Faghri, Review and advances of direct methanol fuel cells: Part II: Modeling and numerical simulation, J. Power Sources. 230 (2013) 303-320. doi:10.1016/j.jpowsour.2012.12.009.

[24] A.J. Bard, L.R. Faulkner, Electrochemical Methods: Fundamentals and Applications, 2nd ed., John Wiley \& Sons, 2001.

[25] J. Donea, A. Huerta, J. Ponthot, A. Rodr, Arbitrary Lagrangian - Eulerian Methods, in: Encycl. Comput. Mech., 1999: pp. 1-25. doi:10.1002/0470091355.ecm009.

[26] W.A. Tucker, L.H. Nelken, Diffusion Coefficients in Air and Water, in: W.J. Lyman, W.F. Reehl, D.H. Rosenblatt (Eds.), Handb. Chem. Prop. Estim. Methods, American Chemical Society, Washington DC, 1982.

[27] J. Read, K. Mutolo, M. Ervin, W. Behl, J. Wolfenstine, A. Driedger, et al., Oxygen Transport Properties of Organic Electrolytes and Performance of Lithium/Oxygen Battery, J. Electrochem. Soc. 150 (2003) A1351-A1356. doi:10.1149/1.1606454.

[28] T.E. Daubert, R.P. Danner, Physical and Thermodynamic Properties of Pure Chemicals: Data Compilation, Taylor \& Francis, Washington, DC, 1989.

[29] D.T. Sawyer, G. Chlerlcato, C.T. Angells, E.J. Nannl, T. Tsuchlya, Effects of Media and Electrode Materials on the Electrochemical Reduction of Dioxygen, Anal. Chem. 54 (1982) 1720-1724. doi:10.1021/ac00248a014.

[30] J.P. Southall, H.V.S.A. Hubbard, S.F. Johnston, V. Rogers, G.R. Davies, J.E. McIntyre, et al., Ionic conductivity and viscosity correlations in liquid electrolytes for incorporation into PVDF gel electrolytes, Solid State Ionics. 85 (1996) 51-60.

[31] B.T. Ahn, H. Jeon, B.Y. Hur, K. Kim, J.W. Park, Effect of Various Lithium Salts in TEGDME Based Electrolyte for Li/Pyrite Battery, Solid State Phenom. 124-126 (2007) 971-974. doi:10.4028/www.scientific.net/SSP.124-126.971.

[32] K.M. Abraham, Z. Jiang, A Polymer Electrolyte-Based Rechargeable Lithium/Oxygen Battery, J. Electrochem. Soc. 143 (1996) 1. doi:10.1149/1.1836378. 
[33] S.G. Stewart, J. Newman, The Use of UV/vis Absorption to Measure Diffusion Coefficients in $\mathrm{LiPF}_{6}$ Electrolytic Solutions, J. Electrochem. Soc. 155 (2008) F13-F16. doi:10.1149/1.2801378.

[34] Y.-C. Lu, D.G. Kwabi, K.P.C. Yao, J.R. Harding, J. Zhou, L. Zuin, et al., The discharge rate capability of rechargeable $\mathrm{Li}_{2} \mathrm{O}_{2}$ batteries, Energy Environ. Sci. 4 (2011) 2999-3007. doi:10.1039/c1ee01500a. 


\section{Table captions}

Table 1 Structural parameters of the Li-air coin cell

Table 2 Effective domains of each dependent variable and corresponding boundary and initial conditions

Table 3 Solvent/Electrolyte properties of the Li-air coin cell

Table 4 Parameters used in the simulation model of a Li-air coin cell 
Table 1 Structural parameters of the $\mathrm{Li}$-air coin cell

\begin{tabular}{|c|c|c|c|c|c|c|c|c|}
\hline \multicolumn{2}{|c|}{ Radius [mm] } & \multicolumn{4}{|c|}{ Original thickness $[\mathrm{mm}]$} & \multicolumn{3}{|c|}{ Original porosity } \\
\hline rodes & Opening & GDL & Cathode & Separator & Anode & GDL & Cathode & Separator \\
\hline 2.5 & 0.1 & 0.1 & 0.8 & 0.025 & 0.2 & 0.75 & 0.73 & 0.5 \\
\hline
\end{tabular}


Table 2 Effective domains of each dependent variable and corresponding boundary and initial conditions

\begin{tabular}{|c|c|c|}
\hline Variable & Effective Domain & Boundary Condition (BC) and Initial Condition (IC) \\
\hline$c_{\mathrm{Li}}$, eq. (6) & Sep*, Cath ${ }^{*}$ & $\begin{array}{l}\text { (1) }^{* *}: \frac{\partial c_{\mathrm{Li}}}{\partial z}=0 ;(3):-D_{\mathrm{Li}}^{e f f} \frac{\partial c_{\mathrm{Li}}}{\partial z}=\frac{1-t_{+}}{\mathrm{F}} I \\
\text { IC: } c_{\mathrm{Li}}=1 \mathrm{M}\end{array}$ \\
\hline$c_{0_{2}}$, eq. (8) & Sep, Cath & $\begin{array}{l}\text { (1): } c_{\mathrm{O}_{2}}=\frac{c_{o a}}{c_{0}} c_{\mathrm{O}_{2}, s a t} ; \text { (3): } \frac{\partial c_{\mathrm{O}_{2}}}{\partial z}=0 \\
\text { IC: } c_{\mathrm{O}_{2}}=c_{\mathrm{O}_{2}, \text { sat }}\end{array}$ \\
\hline$\phi_{2}$, eq. (12) & Sep, Cath & $\begin{array}{l}\text { (1): } \frac{\partial \phi_{2}}{\partial z}=0 ;(3):-k^{e f f} \frac{\partial \phi_{2}}{\partial z}=I+\frac{k_{D}}{c_{\mathrm{Li}}} \frac{\partial c_{\mathrm{Li}}}{\partial z} \\
\text { IC: } \phi_{2}=0\end{array}$ \\
\hline$\phi_{1 c}$, eq. (15) & Cath, GDL ${ }^{*}$ & $\begin{array}{l}\text { (4): } \frac{\partial \phi_{1 c}}{\partial z}=0 ; \text { (5): } \frac{\partial \phi_{1 c}}{\partial z}=0 ; \text { (6): }-k_{c}^{e f f} \frac{\partial \phi_{1 c}}{\partial z}=\frac{I}{1-O_{r}} \\
\text { IC: } \phi_{1 c}=E_{0}^{c}\end{array}$ \\
\hline$c_{o a}$, eq. (16) & $\mathrm{GDL}, \mathrm{AC}^{*}$ & $\begin{array}{l}\text { (1): } N_{o a}=N_{O_{2}} ;(8): N_{o a}=0 \\
\text { IC: } c_{o a}=0.21 c_{0}\end{array}$ \\
\hline$c_{s a}$, eq. (17) & GDL, AC & $\begin{array}{l}\left.\text { (1): } c_{s a}=\frac{p_{s a}}{p_{0}} c_{0} ; 8\right): N_{o a}=0 \\
\text { IC: } c_{s a}=0\end{array}$ \\
\hline$\phi_{1 a}$, eq. (27) & Ano ${ }^{*}$ & $\begin{array}{l}\text { (2): } \phi_{1 a}=0 ;(3):-k_{L i} \frac{\partial \phi_{1 a}}{\partial z}=I \\
\text { IC: } \phi_{1 a}=0\end{array}$ \\
\hline$\varepsilon_{\mathrm{s}}$, eq. $(21)$ & Sep, Cath & IC: $\varepsilon_{\mathrm{s}}=0$ \\
\hline
\end{tabular}

* Sep: Separator; Cath: Cathode; GDL: Gas Diffusion Layer; AC: Air Chamber; Ano: Anode.

** (1) - (8): Boundaries shown in Figure 2. 
Table 3 Solvent/Electrolyte properties of the Li-air coin cell

\begin{tabular}{lccc}
\hline & & DMF & TEGDME \\
\hline Diffusion coefficient in air $\left[\times 10^{-6} \mathrm{~m}^{2} \mathrm{~s}^{-1}\right]$ & $D_{\text {so }}$ & 9.49 & 5.13 \\
Vapor pressure [Pa] & $p_{\mathrm{s}}$ & $516[28]$ & 1.33 \\
Molecular weight $\left[\mathrm{g} \mathrm{mol}^{-1}\right]$ & $M_{s}$ & 73.09 & 78.13 \\
Density $\left[\mathrm{kg} \mathrm{m}^{-3}\right]$ & $\rho_{s}$ & 948 & 1100.4 \\
$\mathrm{O}_{2}$ solubility $\left[\mathrm{mol} \mathrm{m}^{-3}\right]$ & $c_{O_{2}, \text { sat }}$ & $4.8[29]$ & $4.84[27]$ \\
$\mathrm{O}_{2}$ diffusivity $\left[\times 10^{-9} \mathrm{~m}^{2} \mathrm{~s}^{-1}\right]$ & $D_{O_{2}}$ & 1.93 & $0.217[10]$ \\
Ionic conductivity $[\mathrm{S} / \mathrm{m}]$ & $k_{\mathrm{e}}$ & $1.0[30]$ & $0.06[31]$ \\
\hline
\end{tabular}


Table 4 Parameters used in the simulation model of a Li-air coin cell

\begin{tabular}{lll}
\hline Parameter & Symbol & Value \\
\hline Cathode specific area $\left[\mathrm{m}^{2} \mathrm{~m}^{-3}\right]$ & $A_{\mathrm{ED}, 0}$ & $3.75 \times 10^{6}[4]$ \\
Cathode rate constant $\left[\mathrm{A} \mathrm{m}^{-2}\right]$ & $k_{R}$ & $2.5 \times 10^{-9}$ \\
Transfer coefficient & $\alpha_{\mathrm{c}}, \alpha_{a}$ & 0.5 \\
Cathode theoretical potential $[\mathrm{V}]$ & $E_{\mathrm{c}}^{0}$ & $3.1[32]$ \\
Anode exchange current density $\left[\mathrm{A} \mathrm{m}{ }^{-2}\right]$ & $i_{0}$ & $1[5]$ \\
Density of lithium $\left[\mathrm{g} \mathrm{cm}^{-3}\right]$ & $\rho_{\mathrm{Li}}$ & 0.534 \\
Density of carbon $\left[\mathrm{g} \mathrm{cm}^{-3}\right]$ & $\rho_{\mathrm{c}}$ & 2.0 \\
Density of lithium peroxide $\left[\mathrm{g} \mathrm{cm}^{-3}\right]$ & $\rho_{\mathrm{Li}_{2} \mathrm{O}_{2}}$ & 2.14 \\
Density of PTFE $\left[\mathrm{g} \mathrm{cm}^{-3}\right]$ & $\rho_{\mathrm{PTFE}}$ & 2.2 \\
Electric resistivity of $\mathrm{Li}_{2} \mathrm{O}_{2}\left[\Omega \mathrm{m}^{2}\right]$ & $R_{\mathrm{Li} \mathrm{O}_{2}}$ & $50[4]$ \\
Salt diffusivity in electrolyte $\left[\mathrm{m}^{2} \mathrm{~s}^{-1}\right]$ & $D_{\mathrm{Li}}$ & $1.5 \times 10^{-10}[33]$ \\
Molecular weight of lithium $\left[\mathrm{g} \mathrm{mol}^{-1}\right]$ & $M_{\mathrm{Li}}$ & 6.94 \\
Molecular weight of $\mathrm{Li}_{2} \mathrm{O}_{2}\left[\mathrm{~g} \mathrm{~mol}^{-1}\right]$ & $M_{\mathrm{Li} \mathrm{O}_{2}}$ & 45.88 \\
Transference number & $t_{0}^{+}$ & $0.43[34]$ \\
Thermodynamic factor & $1+d \mathrm{nn} f_{ \pm} / d \mathrm{lnc}$ & $0.1287 c_{\mathrm{Li}}{ }^{3}-0.4106 c_{\mathrm{Li}}{ }^{2}+0.4717 c_{\mathrm{Li}}+0.5508$ \\
\hline
\end{tabular}




\section{Figure captions}

Figure 1 Structure of a Li-air coin cell.

Figure 2 Computational domain and boundaries of the Li-air coin cell.

Figure 3 Comparison of predicted battery discharge curves at various current densities with experimental results from Read [16].

Figure 4 Variation of electrolyte surface and anode/spring interface position with time for a Liair coin cell using (a) DMF and (b) TEGDME as electrolyte solvent.

Figure 5 Discharge curves with and without consideration of electrolyte level change for a Liair coin cell using (a) DMF and (b) TEGDME as electrolyte solvent.

Figure $6 \mathrm{Li}_{2} \mathrm{O}_{2}$ deposition on the cathode solid phase surface (a) with constant electrolyte level and (b) with electrolyte level drop.

Figure 7 Distribution of $\mathrm{Li}_{2} \mathrm{O}_{2}$ deposition volume fraction, $\varepsilon_{\mathrm{s}}$, with and without consideration of electrolyte level drop.

Figure 8 Discharge curves with various air chamber radii and DMF as electrolyte solvent. 


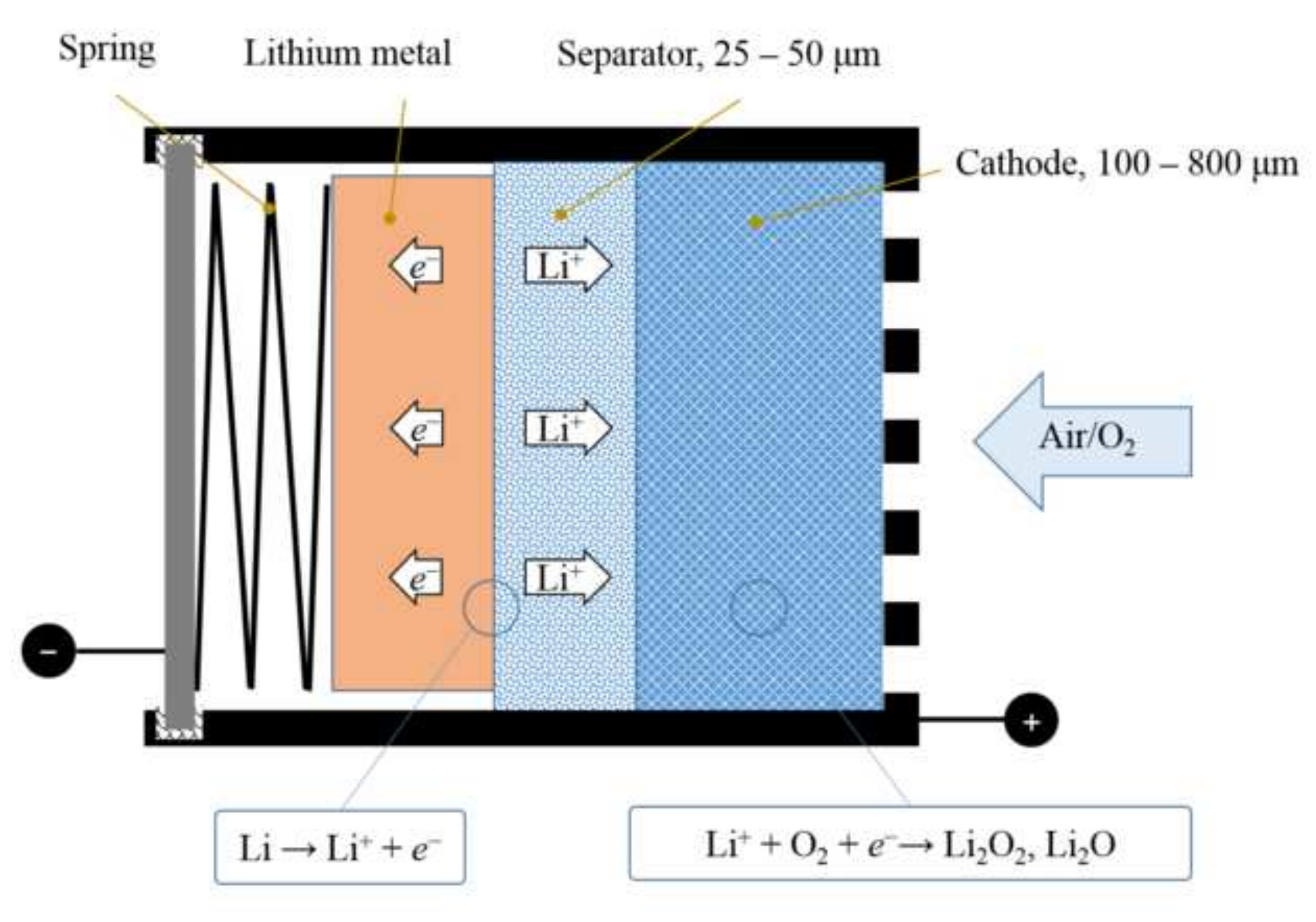

Figure 1

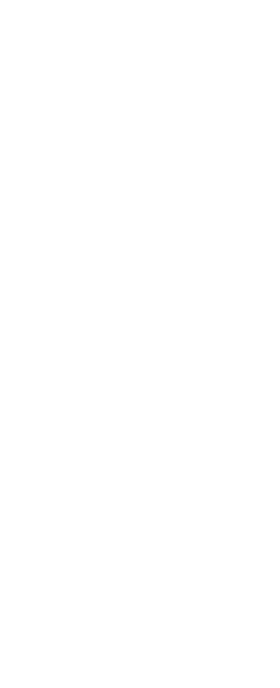




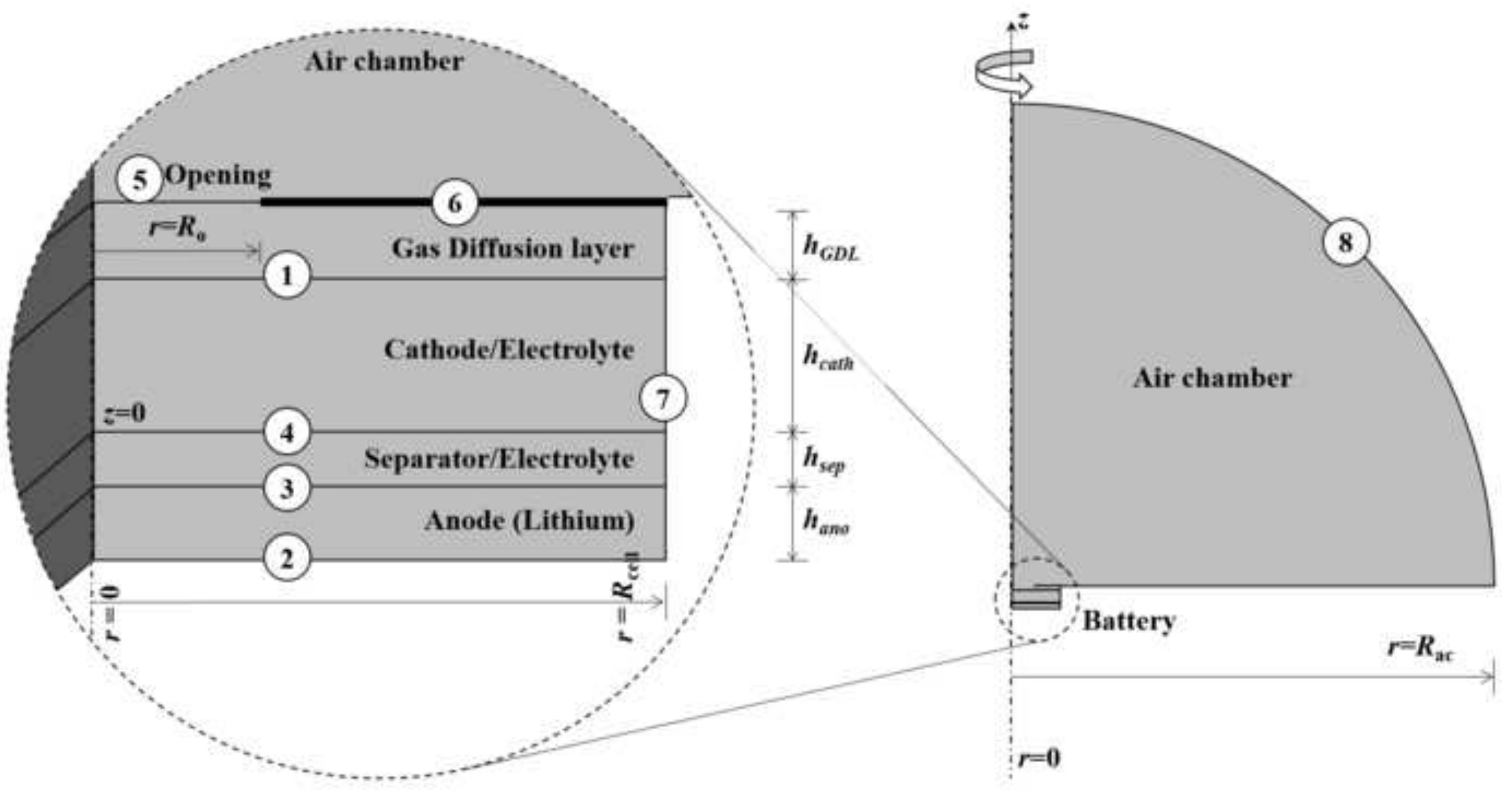




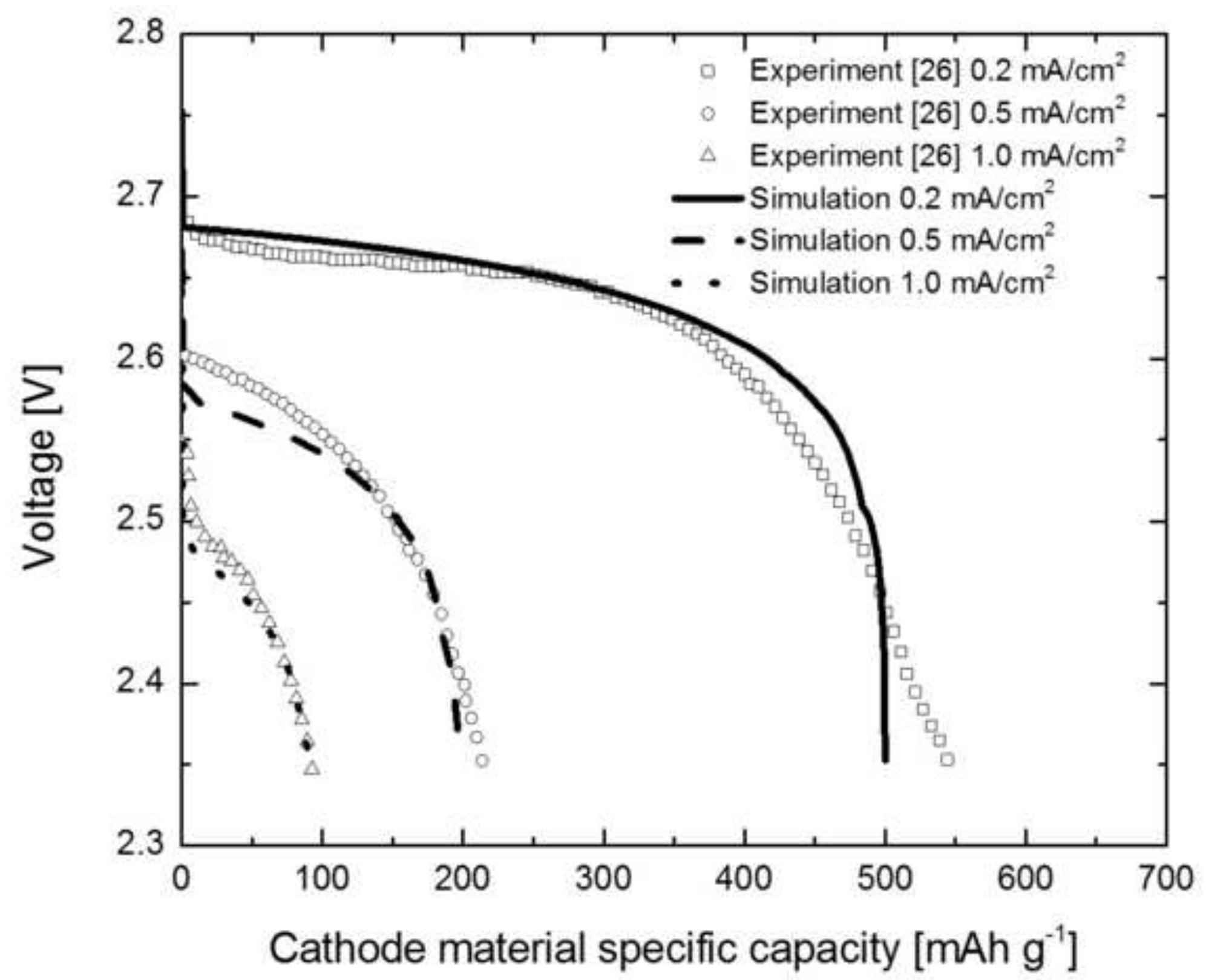




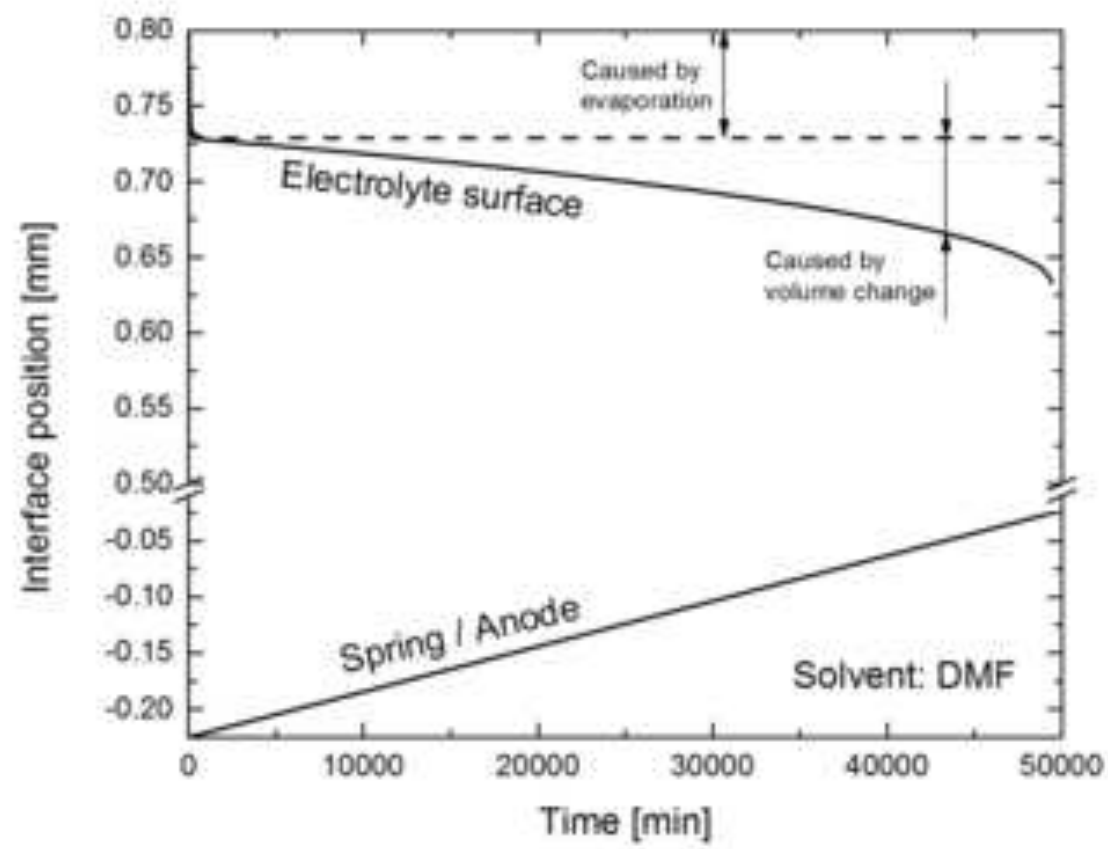

(a)

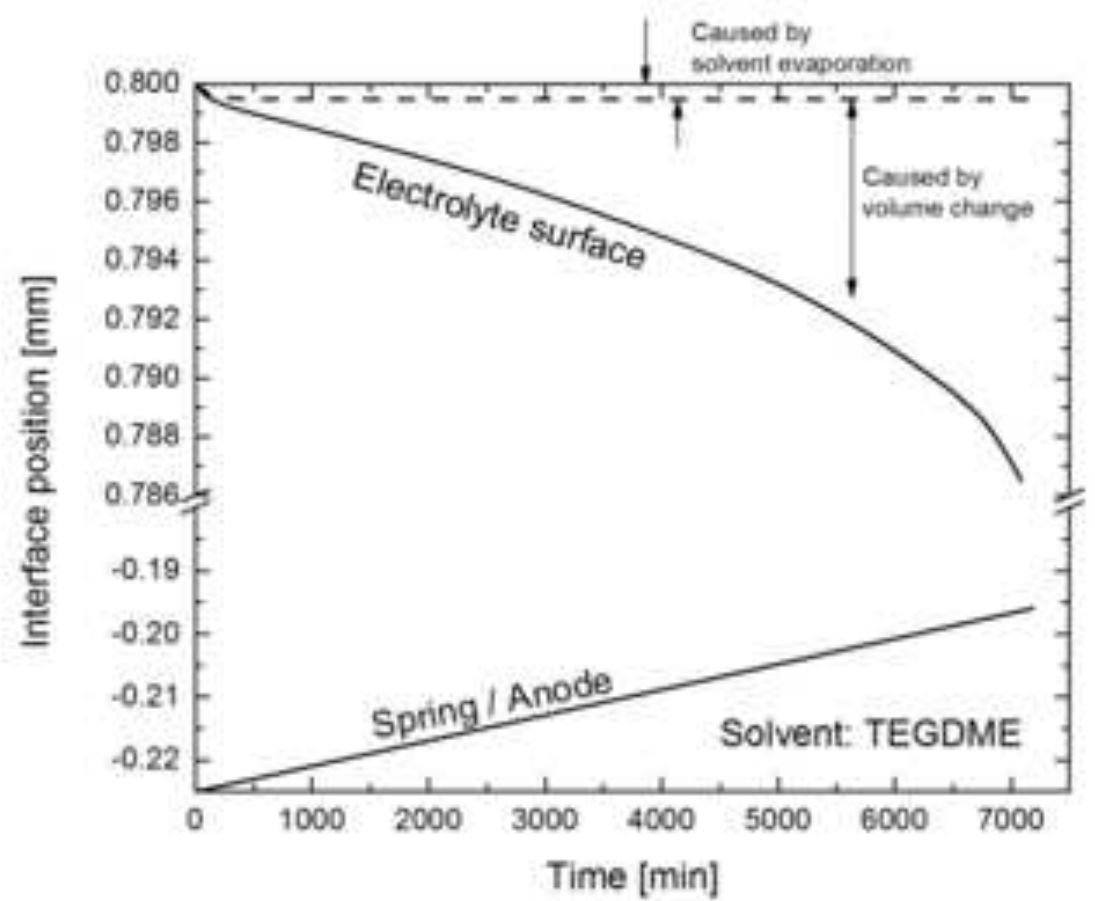

(b) 


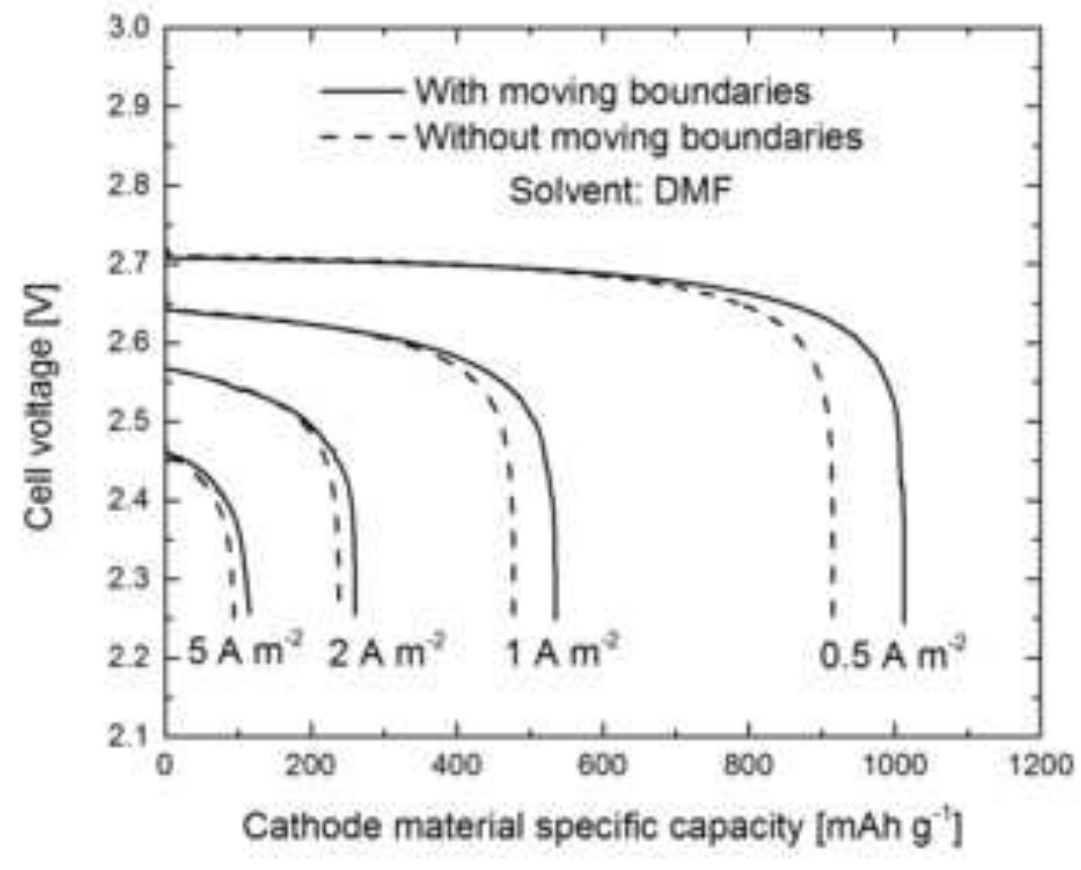

(a)

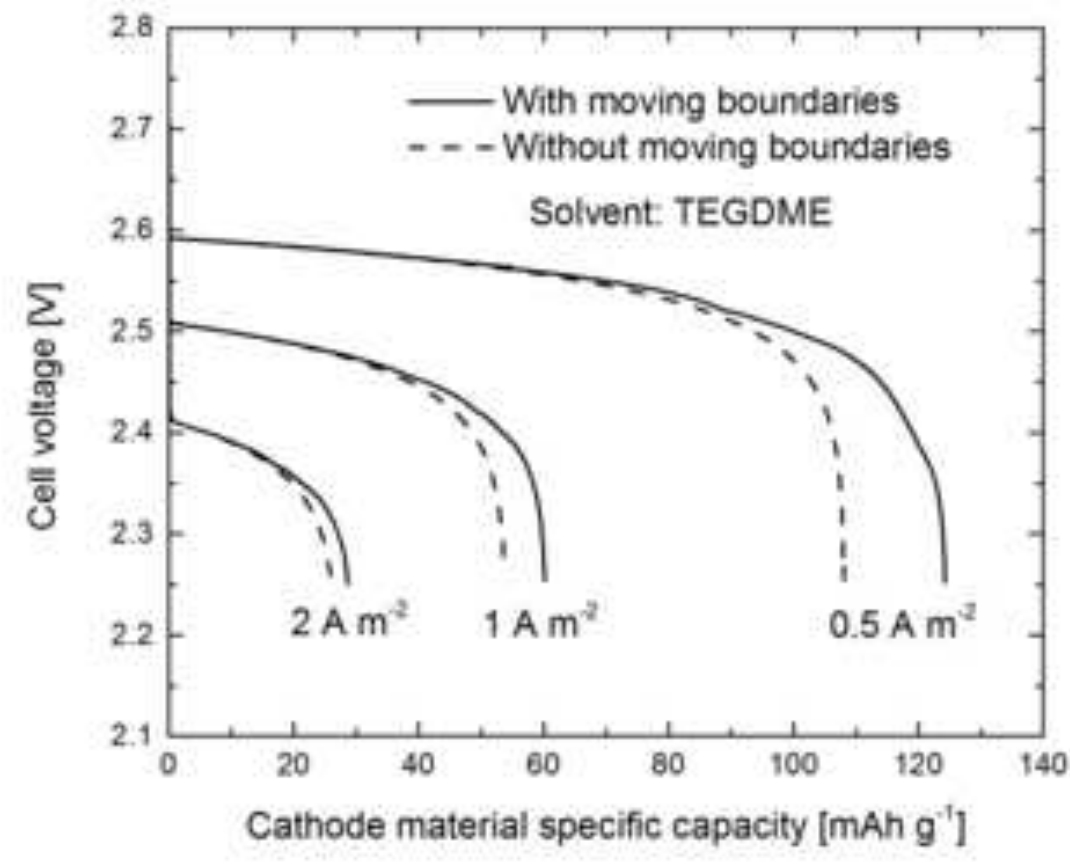

(b) 


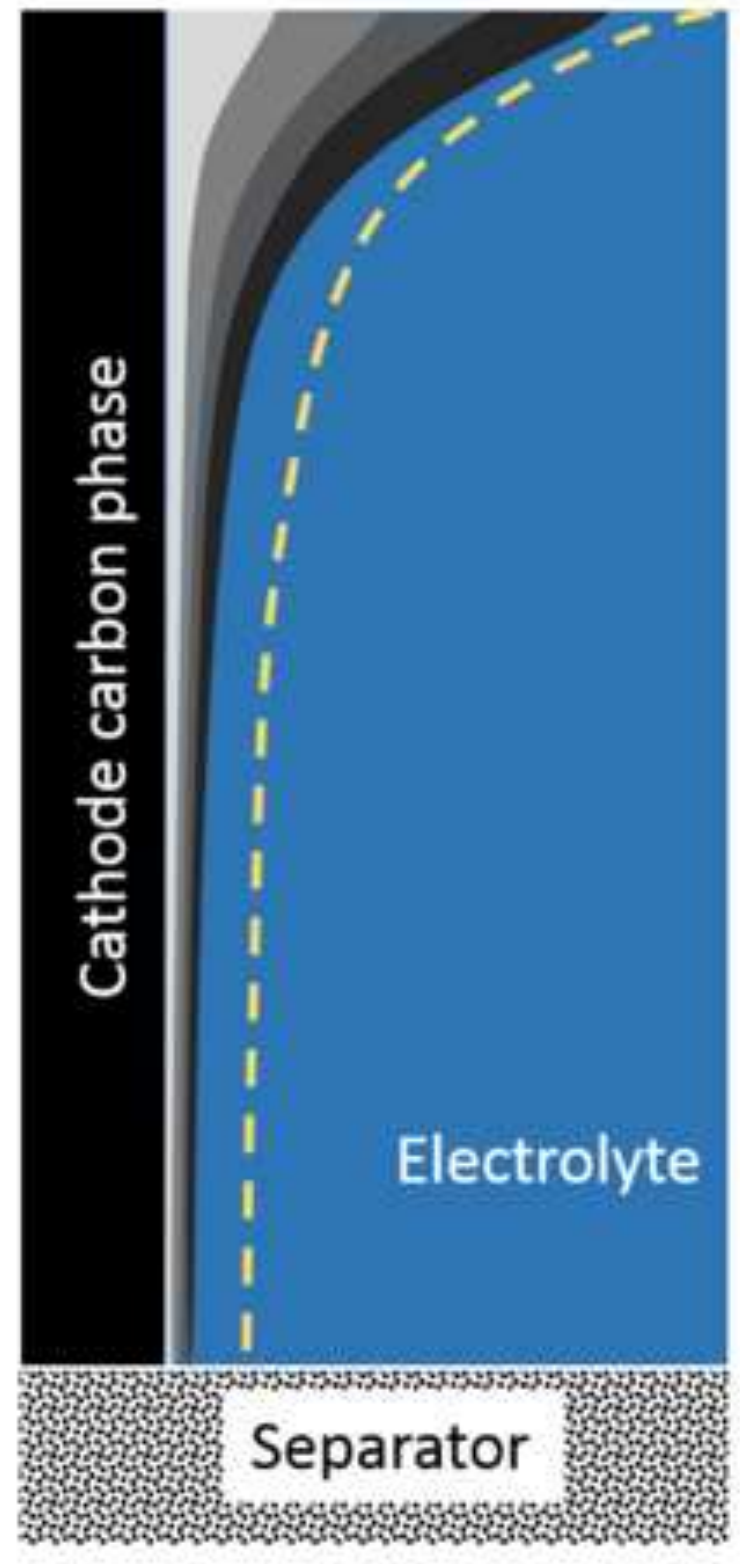

(a)

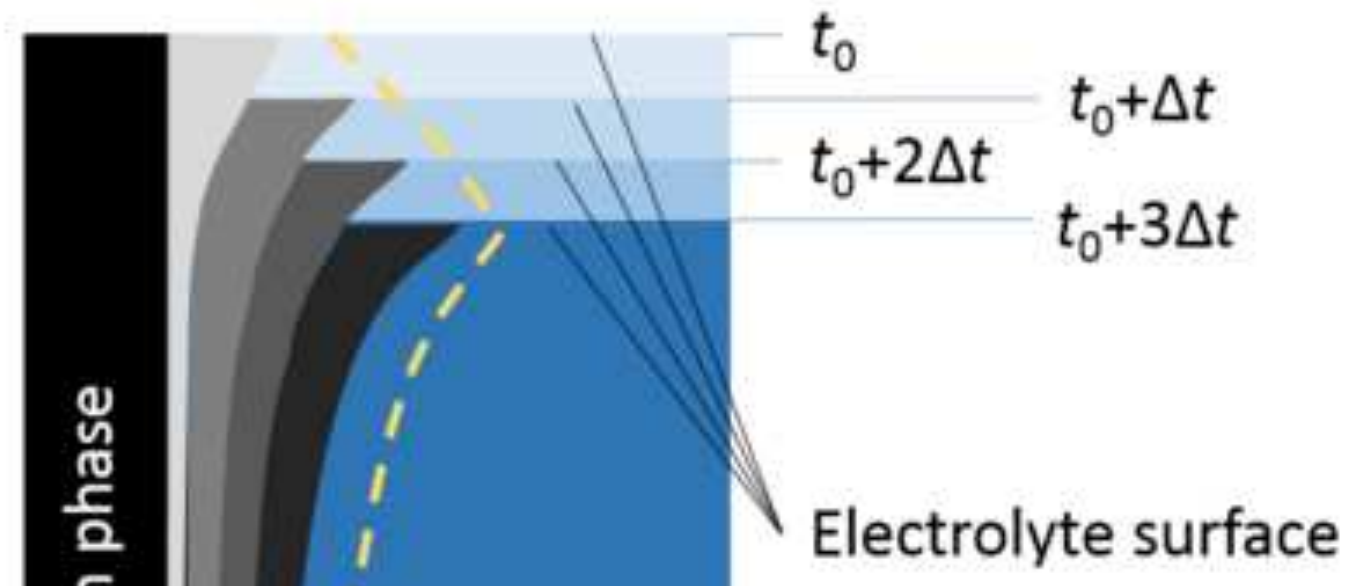

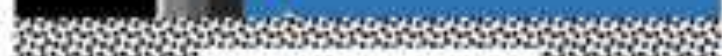

Separator

430 s

(b) 
Cathode/GDL

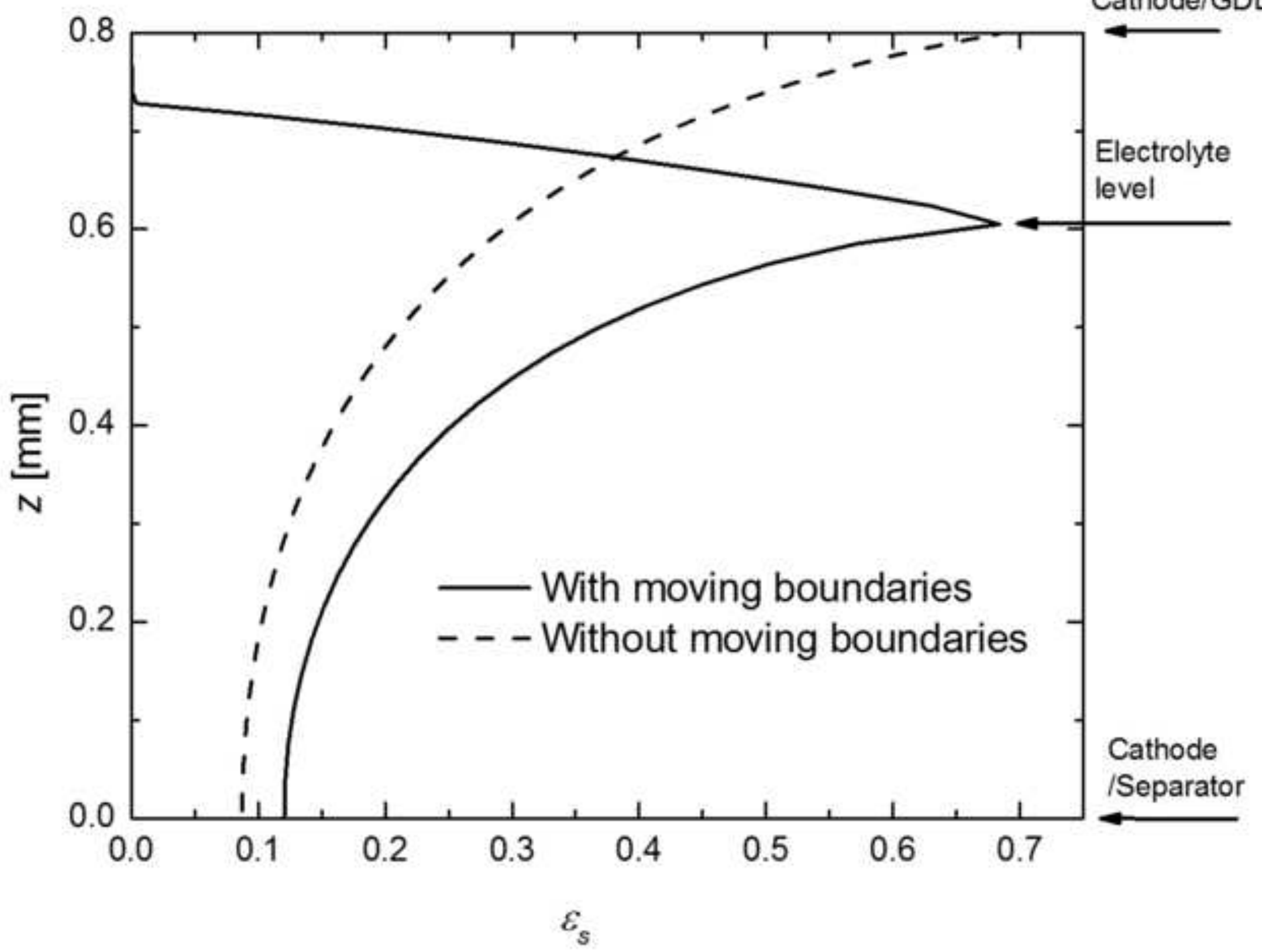




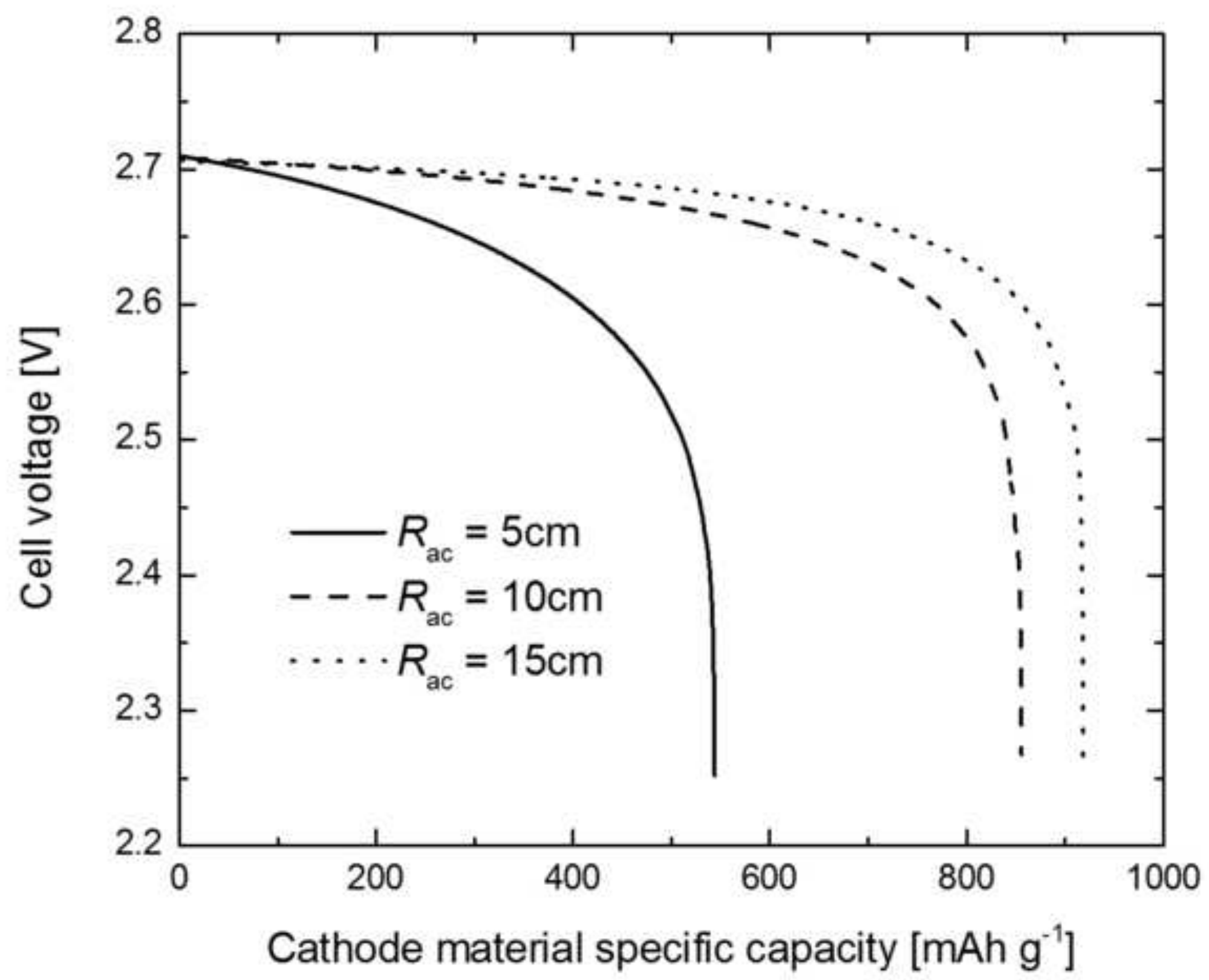

